\title{
Correction to: Preparation of GO/MIL-101(Fe,cu) composite and its adsorption mechanisms for phosphate in aqueous solution
}

\section{You Wu ${ }^{1} \cdot$ Zhuannian Liu $^{1} \cdot$ Mohammad Fahim Bakhtari $^{1}$ - Junnan Luo ${ }^{1}$}

Published online: 23 July 2021

(C) Springer-Verlag GmbH Germany, part of Springer Nature 2021

Correction to: Environmental Science and Pollution Research https://doi.org/10.1007/s11356-021-14206-9

The correct name of the 2nd Author is presented in this paper. The original article has been corrected.

Publisher's note Springer Nature remains neutral with regard to jurisdictional claims in published maps and institutional affiliations.

The online version of the original article can be found at https://doi.org/ 10.1007/s11356-021-14206-9

You Wu

securewyy@126.com

1 College of Geology and Environment, Xi'an University of science and technology, Xi'an 710054, People's Republic of China 